\title{
Estimating the Length of the First Antiretroviral Therapy Regiment Durability in São Paulo, Brazil
}

Roseane Medeiros, Ricardo S. Diaz and Adauto Castelo Filho

\author{
Infectious Diseases Division, Paulista School \\ of Medicine, Federal Medical School of São \\ Paulo, SP, Brazil
}

\begin{abstract}
Brazil was the first country to provide unrestricted, cost-free access to antiretroviral (ARV) medicine for AIDS treatment. However, there is little data about the benefits of such a policy for these patients. We evaluated the duration of benefit obtained with the introduction of ARVs, defined as the durability of the first ARV regiment. We reviewed the medical charts of patients attended from 1996-2000, at the outpatient clinics of the Federal University of São Paulo, Brazil. A total of 120 drug-naive HIV-1 infected patients were eligible to participate in the study. About half of the individuals $(53 \%)$ presented with disease symptoms; $59 \%$ of them had $\mathrm{CD}_{4}$ count below 200 cells $/ \mathrm{mm}^{3}$. Mean estimated duration of the benefit of therapy was 14.1 months. The most used regimen in this cohort was Zidovudine/3TC/Indinavir (26\%), followed by Zidovudine/ DDI (17\%), and Zidovudine/3TC/Nelfinavir (13\%). The most frequent cause of interruption of therapy was gastrointestinal intolerance. Use of treatment regimens with three drugs was more effective than with two drugs, but only for patients with $\mathrm{CD}_{4}<200$ cells $/ \mathrm{mm}^{3}$ or $\mathrm{CV}>100,000$ copies RNA/mL. However, the use of triple therapy was associated with a significantly higher probability of reaching maximum viral suppression, during a longer period $(p<0.05)$. The patients enrolled in the study benefitted from therapy for a limited time, after the introduction of double or triple antiretroviral therapy. The incidence of adverse events was significantly associated with loss of the benefits provided by the initial therapeutic regimen.
\end{abstract}

Key Words: Zidovudine, antiretroviral therapy, São Paulo, Brazil.

Highly active antiretroviral therapy (HAART) is the standard of care for treatment of AIDS patients in Brazil, since 1997 [1]. In Brazil, the distribution of antiretroviral (ARV) drugs was regulated by Brazilian Ministerial Act number 21 on March 21, 1995. Next, the Health Ministry created a technical committee that would propose the Therapeutic Guidelines for HIV to be used in the purchase, distribution, and prescription of ARV. On December 21, 1995 the work culminated with

Received on 25 May 2002; revised 18 September 2002. Address for correspondence: Dr. Adauto Castelo. Av Jandira 610 apto 32, Zip code: 04080-004, São Paulo-SP. Phone: 55-115549-0158.Fax:55-11-5575-6427.E-mail:acastelo @originet.com.br This work was supported by Ministry of Science and Technology grant \# 41.96.0943-00 (Pronex).

The Brazilian Journal of Infectious Diseases 2002;6(6):298-304 (C) 2002 by The Brazilian Journal of Infectious Diseases and Contexto Publishing. All rights reserved. $1413-8670$
Decree \# 9313 on November 13, 1996, granting free access to the medication necessary for ARV treatment and the beginning of the distribution of the triple treatment containing PI [2].

Along with the antiretroviral availability policy the Health Ministry has strengthened the country's public laboratories to provide the surrogate markers for HIV infection $\left(\mathrm{CD}_{4}^{+}\right.$lymphocyte counts and HIV RNA viral load). Presently about 120,000 individuals obtain ARV drugs from the public health network. These patients are concentrated in the Southeast region (70\%), mainly in São Paulo (44\%) and Rio de Janeiro (20\%), followed by the Southern (17\%), Northeastern (7\%), Central-West (4\%) and Northern (29\%) regions [3].

The estimate of total expenditure with antiretroviral (ARV) drugs was US\$250 million in 2000. There is scarce information about the impact 
of ARV therapy on the quality of life of AIDS patients in Brazil, and about the duration of the benefit of HAART for them.

It is important to stress that incomplete adherence favors viral escape, which is associated with a short period of virological response and which accelerates the onset of viral strains with a resistance profile [4].

We studied the duration of the therapeutic benefit of the Health Ministry ARV distribution scheme in the Federal University of São Paulo (UNIFESP) specialized outpatient clinics for HIV in HIV-infected patients who had no prior treatment. We also evaluated the impact of demographic-clinical variables, $\mathrm{CD}_{4}$ cell counts and pre-treatment HIVRNA on the duration of the therapeutic benefit; and we examined the reasons for the cessation of ARV benefits of the various therapeutic schemes used in these patients.

\section{Material and Methods}

Location of the study

The study was conducted at the Outpatient Clinics (CCDI) of (UNIFESP), Brazil. The CCDI is a dedicated outpatient HIV/AIDS clinic where over 1,000 patients receive care.

\section{$\underline{\text { Study design and patient population }}$}

A retrospective cohort was evaluated. All patients receiving care at CCDI during the study period were eligible for the study, if they fulfilled the following criteria: age over 15 years, Western blot confirmed HIV-1 infection, no previous ARV experience and availability of $\mathrm{CD}_{4}$ and plasma viral load determinations at baseline and after six months of therapy.

Medical charts were reviewed and demographic data, clinical status at the first medical evaluation, ARV regimens prescribed, viral load/CD $\mathrm{CD}_{4}$ determinations, and outcome after six months of follow up were recorded. All the data were stored in a databank, and analyzed by using the software EPI-Info version 6.02, SAS, and SPSS version 9.0.

\section{Laboratory tests}

All viral load determinations were performed by NASBA (Organon Teknika, The Netherlands), with a sensitivity limit of $400 \mathrm{HIV}-1$ RNA copies/ml of plasma. The measurement of $\mathrm{CD}_{4}^{+} / \mathrm{CD}_{8}^{+}$lymphocytes was made by flow cytometry.

\section{Treatment failure criteria}

For the purpose of this study, we defined treatment failure/cessation of therapy benefit (first ARV regimen durability) as the occurrence of at least one of the following conditions: (i) Viral load higher than 1,000 copies/ml after six months of therapy; (ii) Increase in $\mathrm{CD}_{4}$ count of less than $10 \%$ of baseline values, after the same period of time; (iii) Treatment interruption due to drug intolerance; (iv) Death, or therapy abandonment; (v) Need for treatment intensification.

\section{Results}

Eight hundred medical charts were reviewed, corresponding to the total number of patients attended at CCDI from 1996 to 2000 . One hundred and twenty patients met the inclusion criteria and had their medical records reviewed. Most (72.5\%) of the patients were male. The most frequently reported $(70 \%)$ route of HIV transmission was unprotected heterosexual contact. Bisexual activity was reported by $18 \%$ of the men, while intravenous drug use was considered the source of infection by $10 \%$ of the patients. Only $2 \%$ of them were contaminated by transfusion of HIV-infected blood products. As expected, women were more likely to report heterosexual contact as the route of infection than men (94\% vs. $82 \%$, for women and men, respectively, $\mathrm{p}=0.003$, Yates corrected). About half (53\%) of subjects presented clinical symptoms at the first medical evaluation. Table 1 summarizes the characteristics of the patients.

At baseline, the mean $\mathrm{CD}_{4}^{+}$cell count was 204 cells/ $\mathrm{mL}$ (median 163 cells $/ \mathrm{mL}$ ), and the mean viral load (VL) was 293,000 RNA copies/mL of plasma (median 110,000 copies/mL). 
Women had a significantly higher $\mathrm{CD}_{4}$ count $(251 \pm 177$ cells $/ \mathrm{mL})$ than men $(197 \pm 199$ cells $/ \mathrm{mL}$, $\mathrm{p}=0.047$ ), but no difference was seen for VL values $(\mathrm{p}=0.3)$. Table 2 shows the patients' laboratory findings.

Therapy regimen and duration of treatment benefit (first time regiment durability)

We detected 25 different treatment regimens. Individuals assigned to receive therapy with only two ARV drugs (29\% of the total) had a baseline $\mathrm{CD}_{4}$ count higher than those receiving triple therapy (330 and 164 cells/mL, respectively, $\mathrm{p}<0.001)$. We also observed a relationship between VL values and choice of therapy regimen (87,560 copies/mL, and 394,896 copies/mL for patients prescribed two and three ARV drugs, respectively, $\mathrm{p}=0.002$ ).

Viral suppression (defined as VL values below the detection limit after six months of therapy) was achieved in $56 \%$ of the patients. Patients under triple therapy were more likely to have achieved viral suppression than those using only two drugs (67\% vs. $34 \%$ for patients using three and two drugs, respectively, $\mathrm{p}=0.002$ ). The mean duration of the treatment benefit was 14.1 months, but $23 \%$ of individuals had lost it after six months of therapy. After 12 months, only $47 \%$ of patients still maintained a therapy benefit.

The major reason for changing ARV drugs was intolerance, which affected $22.5 \%$ of the patients. Absence of virological response (22.5\%), and viral rebound $(19.2 \%)$ were the other two major reasons for changes in treatment. Table 3 displays the patients' outcome according to the type of treatment they received.

The results demonstrate that patients using three drugs were more likely to maintain the treatment benefit for a longer time (>12 months), than those receiving only two drugs $(\mathrm{p}=0.047)$. However, when the therapy regimen was adjusted for $\mathrm{CD}_{4}$ levels (threshold value $=200$ cells $/ \mathrm{mL}$ ) that difference remained significant only for patients with $\mathrm{CD}_{4}<200$ cells $/ \mathrm{mL}(\mathrm{p}=0.01)$, but not for those with higher $\mathrm{CD}_{4}$ counts $(\mathrm{p}=0.4)$.
A similar finding was seen when adjusting the effect of treatment to baseline VL results: patients with VL $>100,000$ copies/mL had a greater benefit when using three drugs $(\mathrm{p}=0.03)$. Moreover, the proportion of patients achieving undetectable VL, at any point during treatment, was significantly higher for patients using three than two drugs $(67 \%$ vs. $34 \%$, respectively, $\mathrm{p}=0.002$ ), regardless of baseline VL or $\mathrm{CD}_{4}$ counts. Interestingly, 7 out of 23 patients "failing" double therapy (30\%), interrupted treatment due to either intolerance or self-imposed discontinuation, whereas the remaining 16 patients discontinued therapy due to virological, immunological or clinical failure. On the other hand, 21 out of 35 individuals failing triple therapy interrupted treatment due to intolerance or self discontinuation (Chi-Square $\mathrm{p}<0.05)$.

\section{Discussion}

The advent of highly active antiretroviral therapy (HAART) has promoted a tremendous change in the natural course of HIV infection [5]. Following the introduction of HAART, there has been a significant improvement in the quality and duration of patient life [6]. However, new adverse events were detected, as treatment became longer, and more complex, which also brings up increased concern about patient compliance. These facts have led to a search for simpler and less toxic drug combinations. In addition, the occurrence of side effects, and/or low compliance has been associated with a high risk of HIV resistance to antiretroviral drugs, which causes therapy failure [79]. Another potential cause of treatment failure is suboptimal therapy, leading to incomplete viral suppression and consequent selection of HIV-resistant variants.

In Brazil, the government has provided free of cost AIDS treatment for the last 10 years. There is a consensual opinion that the Brazilian Program to AIDS control has been successful in avoiding the spread of the AIDS epidemic in this country, but there is little data about the actual extent of the benefit and its durability, for Brazilian patients under treatment with antiretroviral drugs. 
Table 1. Patient demographics and characteristics $(n=120)$

\begin{tabular}{lcc}
\hline Gender & Number & $\%$ \\
Men & 87 & 72.5 \\
Women & 33 & 27.5 \\
Age (years) & & \\
$\quad$ Median overall & 36 & \\
Median male & 36.9 & \\
Median female & 33.6 & \\
$\quad$ Variation & $15-69$ & 70 \\
Risk Factors & & 18.3 \\
$\quad$ Heterosexual & 84 & 10 \\
Homo-bisexual & 22 & 1.7 \\
IDU & 12 & \\
Blood transfusion & 2 & 47.5 \\
Status Clinic & & 52.5 \\
$\quad$ Asymptomatic & 57 & \\
Symptomatic & 63 & \\
\hline
\end{tabular}

Table 2. Distribution of patients according to level of CD4 and viral load, at baseline

\begin{tabular}{lrc}
\hline $\mathbf{C D}_{4}$ & $\mathbf{N}$ & \% \\
$\mathrm{CD}_{4}<51$ & 22 & 18.8 \\
$\mathrm{CD}_{4} 51-200$ & 47 & 40.2 \\
$\mathrm{CD}_{4}>200$ & 48 & 41 \\
Total & 117 & 100 \\
\hline HIV-RNA & & \\
CV $<35000$ & 42 & 35 \\
CV 35001-100000 & 21 & 17.5 \\
CV $>100000$ & 57 & 47.5 \\
Total & 120 & 100 \\
\hline
\end{tabular}

Table 3. Duration of the therapeutic benefit by initial triple or double antiretroviral scheme

\begin{tabular}{lccc}
\hline ARV & Duration of the therapeutic benefit & Total \\
\hline 2 NRTI & $<$ 12 months & $>$ 12 months & \\
& 23 & $12 *$ & 35 \\
& $(69.7 \%)$ & $(34.3 \%)$ & $(100 \%)$ \\
2 NRTI + 1 IP & 35 & $42 *$ & 77 \\
& $(45.5 \%)$ & $(54.5 \%)$ & $(100 \%)$ \\
\hline$*_{p}=0.047$. & & &
\end{tabular}


Table 4. Correlation of duration of the therapeutic benefit and initial antiretroviral scheme adjusted to the $\mathrm{CD}_{4}^{+}$ cell counts

\begin{tabular}{|c|c|c|c|c|c|}
\hline \multirow{2}{*}{$\begin{array}{l}\mathrm{CD}_{4}^{+} \text {cells } \\
\text { counts pre-treatment }\end{array}$} & \multirow{2}{*}{$\begin{array}{l}\text { Antiretroviral } \\
\text { scheme used }\end{array}$} & \multicolumn{4}{|c|}{ Duration of the therapeutic benefit } \\
\hline & & $<12$ months & $>12$ months & Total & P value \\
\hline \multirow[t]{2}{*}{$\leq 200$} & 2 NRTI & $\begin{array}{c}7 \\
(100 \%)\end{array}$ & 0 & $\begin{array}{c}7 * \\
(100 \%)\end{array}$ & 0.01 \\
\hline & $2 \mathrm{NRTI}+1 \mathrm{IP}$ & $\begin{array}{c}28 \\
(47.5 \%)\end{array}$ & $\begin{array}{c}31 \\
(52.5 \%)\end{array}$ & $\begin{array}{c}59 * \\
(100 \%)\end{array}$ & \\
\hline \multirow[t]{2}{*}{$>200$} & 2 NRTI & $\begin{array}{c}15 \\
(55.6 \%)\end{array}$ & $\begin{array}{c}12 \\
(44.4 \%)\end{array}$ & $\begin{array}{c}27 * * \\
(100 \%)\end{array}$ & \\
\hline & $2 \mathrm{NRTI}+1 \mathrm{IP}$ & $\begin{array}{c}6 \\
(37.5 \%)\end{array}$ & $\begin{array}{c}10 \\
(62.5 \%)\end{array}$ & $\begin{array}{c}16 * * \\
(100 \%)\end{array}$ & 0.4 \\
\hline
\end{tabular}

Table 5. Correlation of duration of the therapeutic benefit and initial antiretroviral scheme adjusted to HIV viral load

\begin{tabular}{|c|c|c|c|c|c|}
\hline \multirow[t]{2}{*}{ HIV - RNA } & \multirow[t]{2}{*}{ ARV } & \multicolumn{4}{|c|}{ Duration of the therapeutic benefit } \\
\hline & & $<12$ months & $>12$ months & Total & P value \\
\hline \multirow[t]{4}{*}{$\leq 35000$} & 2 NRTI & 8 & 9 & 17 & 0.9 \\
\hline & & $(47.1 \%)$ & $(52.9 \%)$ & $(100 \%)$ & \\
\hline & $2 \mathrm{NRTI}+1 \mathrm{IP}$ & 8 & 12 & 20 & \\
\hline & & $(40.0 \%)$ & $(60.0 \%)$ & $(100 \%)$ & \\
\hline \multirow[t]{4}{*}{35001 to 100000} & 2 NRTI & 6 & 2 & 8 & 0.3 \\
\hline & & $(75.0 \%)$ & $(25.0 \%)$ & $(100 \%)$ & \\
\hline & $2 \mathrm{NRTI}+1 \mathrm{IP}$ & 5 & 6 & 11 & \\
\hline & & $(45.5 \%)$ & $(54.5 \%)$ & $(100 \%)$ & \\
\hline \multirow[t]{4}{*}{$>100000$} & 2 NRTI & 9 & 1 & 10 & 0.03 \\
\hline & & $(90.0 \%)$ & $(10.0 \%)$ & $(100 \%)$ & \\
\hline & $2 \mathrm{NRTI}+1 \mathrm{IP}$ & 22 & 24 & 46 & \\
\hline & & $(47.8 \%)$ & $(52.2 \%)$ & $(100 \%)$ & \\
\hline
\end{tabular}

We acquired some information that can be useful for estimating the duration of the benefits provided by different therapy regimens, as well as how they can be affected by factors such as gender, tolerability, and potency of the drugs used.

As expected, most patients were male, and became infected by a sexual route. About half of them had clinical symptoms at the time of first evaluation. This study was conducted at a public hospital, in São Paulo, the largest and richest Brazilian city, which is also the epicenter of the AIDS epidemic in Brazil. So, we expect that these patients are better informed about HIV infection, and that they have more and easier access to health services than in other regions of the country. However, the fact that many patients had symptoms at the moment that they had their first access to medical care, may indicate that even in São Paulo patients still need more information about AIDS symptoms and risks for acquiring HIV infection. Alternatively, perhaps they do not have easy access 
to medical services, leading to a consequent delay in obtaining medical care before becoming clinically ill, which might be a common feature for the rest of the country $[10,11]$. The low mean $\mathrm{CD}_{4}$ count detected at baseline confirms the advanced status of disease among this population.

Women had a significantly higher $\mathrm{CD}_{4}$ count, when compared to men, at baseline. This fact was also unexpected, since the available information suggests that in Brazil female patients usually seek medical evaluation later than men..

Due to the fact that this study was conducted during two distinct moments of AIDS therapy (including the transition from double to triple therapy as the standard of care), we detected a wide variety of antiretroviral regimens: 25 different drug combinations were encountered; however $71 \%$ of the patients were already using triple therapy. We observed a trend for selection of ARV regimen based on the basal level of $\mathrm{CD}_{4}$ and/or plasma viral load. Thus, patients presenting higher $\mathrm{CD}_{4}$ counts were more likely to be using two rather than three drugs, while those with higher viral loads were more likely to use a triple drug combination.

Not surprisingly was the finding that the proportion of patients achieving complete viral suppression, or maintaining viral suppression for longer than 12 months was significantly higher for those under triple therapy, compared to patients on double therapy. However, according to official figures as many as $25 \%$ of AIDS patients in Brazil are still being treated with double nucleoside therapy [2].

The main reason for changing therapy, in our study, was gastrointestinal intolerance. In other works, sideeffects have been more associated with the use of some specific drugs, such ritonavir, but the diversity of regimens found in our cohort makes this possibility unlikely [12]. Although we did not detect gender differences in the rate of treatment success, it might be interesting to evaluate the risk of failure based on gender, since behavioral differences may contribute to treatment outcomes $[13,14]$. However, the small number of patients included in this cohort do not allow us to make conclusions about the potential effect of gender on therapy success.
The mean duration of the benefit of antiretroviral therapy was around 12 months. However, almost one third of patients, although they received a significant benefit from therapy, were unable to maintain it for six months. Notedly, only $25 \%$ of the patients did not change their regimen during one year of follow up. This fact suggests more efforts are needed, in order to preserve the benefit acquired with therapy, as well as to improve compliance and to guarantee better management of adverse events. If a strategy that focuses on these objectives is implemented, the rate of compliance, and of therapy success may be increased, saving resources, and improving the quality of life of these patients. On the other hand, we think that new studies on these issues are necessary, in order to compare the situation in different regions in Brazil. The evaluation of the results of AIDS treatment around the country would provide an important tool to improve the quality of assistance to these patients, and to optimize the governmental efforts to control this epidemic.

\section{References}

1. Teixeira P.R., Paiva V., Shimma E. Tá difícil de engolir? Experiências de adesão ao tratamento anti-retroviral em São Paulo, São Paulo: Nepaids, 2000. 148 p.

2. http://www.aids.gov.br/assistencia/política-medic-aidsbrasil.htm

3. Brasil. Ministério da Saúde. Divisão Nacional de Doenças Sexualmente Transmissíveis/AIDS. Boletim Epidemiológico AIDS 2000; ano XIII, número 1.

4. Chesney M.A. Factors Affecting Adherence to Antiretroviral Therapy. CID 2000; 30 (Suppl 2): S171-6.

5. Palella F.J., Delaney K.M., Moorman A.C., et al. Declining and mortality among patients with advanced human immunodeficiency virus infection. N Engl J Med 1998;338:853-60.

6. Nieuwkerk P.T., Gisolf E.H., Reijers M.H.E., et al. Longterm quality of life outcomes in three antiretroviral treatment strategies for HIV-1 infection. AIDS 2001;15:1985-91.

7. Lucas G.M., Chaisson R.E., Moore R.D. Highly Active Antiretroviral Therapy in a Large Urban Clinic: Risk Factors for Virologic Failure and Adverse Drug Reactions. Ann Inter Med 1999;131(2):81-7.

8. Kleeberger C.A., Phair J., Strathdee S., et al. Determinants of heterogeneous adherence to HIV - antiretroviral therapies in the multicenter AIDS cohort study. JAIDS 2001;26:82-96. 
9. Ledergerber B., Egger M., Opravil M., et al. Clinical progression and virolgical failure on highly active antiretroviral therapy in HIV patients: a prospective cohort study. Swis HIV Cohort Study. Lancet 1999;353(9156):863-8.

10. Bastos F.I. A Feminização da Epidemia de AIDS no Brasil: Determinantes Estruturais e Alternativas de Enfrentamento. Coleção ABIA, 2001.

11. Dhalia C., Barreira D., de Castilho E.A. A AIDS no Brasil: situação atual e tendências Boletim Epidemiológico AIDS Ano XIII No. 1, Sem Epidem. 48/99 a 22/00, 3-13.

12. Mocroft A., Youle M., Moore A., et al. Reasons for modification and discontinuation of antiretrovirals: results from a single treatment center. AIDS 2000;15:185-94.

13. Barcellos C., Bastos F.I. Redes Sociais e difusão da AIDS no Brasil. Bol Oficina Sanit Panam 1996;1:11-24.

14. Chesney M.A. Factors Affecting Adherence to Antiretroviral Therapy. CID 2000;30(Suppl 2):S171-6. 